\title{
The Primary Exploration of the Teaching Mode ofCollege English Writing Based on Modern Technology
}

\author{
Wang TingTing \\ English Department,Hei Longjiang University of Science and Technology, 150027, China \\ 1062163624@qq.com
}

\begin{abstract}
In the current college English education of our country, the writing education has not got the attention it deserves because of few teaching hours and lacking systematization. The writing education is interspersed among intensive reading course and its tasks are also undertaken by the teachers of intensive reading course; it could not have classes independently. The teaching method it adopted is product-oriented approach, that is taking the works students finally complete as key teaching points with few involvement and guidance during the writing process. The teaching procedure usually includes teachers assigning subject, students completing independently, grading and evaluation. Teaching practice has proved that this teaching method has greater randomness and limitation and is difficult to fully mobilize and exert students' initiative. Therefore, this thesis studies the teaching mode of college English writing based on modern technology in order to provide reference for the college English writing education in our country (Abstract)
\end{abstract}

Keywords-network services; web resource; resource integration

\section{BACKGROUND}

Although the traditional college English education in our country pays equally attention to the four abilities: listening, speaking, reading and writing, writing is not officially the subject necessarily included in English language test in the specific implementation of teaching process until the end of 1980s. Since college English writing course's setting up, teachers and students have not attach importance inwardly to English writing education over a period of time. In recent years, with the deepening of reform and opening up, the increasingly widening of the practical application of English and increasingly frequent communication in network, English writing--the skill which is left out for a time but very important--is gradually gaining people's attention, which symbolizes that English education has entered a new stage. Currently in our country, English writing education is set up the English teaching in both junior college and regular college education, among which writing education in college English for non-English majors is not separated alone, but put in the intensive reading courses like Intensive Reading and College English etc. So teachers can not systematically introduce the basic knowledge of writing, which makes students' writing knowledge system defective and not close enough. It is very hard for the non-English majors who have not taken English writing course to improve their English writing levels.
Though some business colleges and universities open up special business writing course, the course has stronger pertinence and the basic writing education is not comprehensive enough.

The actual English writing education, considering the real teaching situation, of course will inevitably involves two main aspects of teaching and learning-students and teachers. Author does a questionnaire on this issue, interviewing 125 college students including English majors from Hebei University and non-English majors from Heilongjiang University of Science and Technology.

1. Survey results from students

Survey form and measurement standard are shown in table 2-1. We gave out 125 questionnaires and actually collected 125 which includes 4 invalid ones, so the rate of valid questionnaire is $96.8 \%$. The statistical analysis by SPSS of the results is as follows:

Table 1 All the questionnaires The analysis results by SPSS software

\begin{tabular}{cccc}
\hline number & characteristics & articles & percentage \\
\hline 1 & Articles about difficulties and problems in English writing teaching & 29 & $20.7 \%$ \\
2 & Articles about writing teaching approach exploration and reform & 83 & $61.5 \%$ \\
3 & Articles about writing assessment method & 10 & $7.4 \%$ \\
4 & Articles about English writing teaching under the background of Internet & 8 & $5.9 \%$ \\
& & & \\
5 & Articles about other aspects & & $3.7 \%$ \\
& total & 135 & $100 \%$ \\
\hline
\end{tabular}

The importance of all the samples the writing in English learning

The analysis results of SPSS is: $57.9 \%$ of the students think that writing is very important; $26.4 \%$ think that it is quite important; $13.2 \%$ think common; $0.8 \%$ not important.

Table 2 Self-evaluation of writing ability The statistical results by SPSS 


\begin{tabular}{|c|c|c|c|c|c|}
\hline & & Frequency & Percent & $\begin{array}{c}\text { Valid } \\
\text { Percent }\end{array}$ & $\begin{array}{c}\text { Cumulativ } \\
\text { e Percent }\end{array}$ \\
\hline Valid & 1 & 26 & 21.5 & 21.5 & 21.5 \\
\hline & 2 & 24 & 19.8 & 19.8 & 41.3 \\
\hline & 3 & 51 & 42.1 & 42.1 & 83.5 \\
\hline & 4 & 11 & 9.1 & 9.1 & 92.6 \\
\hline & 5 & 9 & 7.4 & 7.4 & 100.0 \\
\hline & Total & 121 & 100.0 & 100.0 & \\
\hline
\end{tabular}

The statistical results of self-evaluation of English writing skills is as follows: only $7.4 \%$ of the students think that their English writing skills are "very good"(5); 42.1\% think their writing skills are common. We can see that the self-evaluation is not optimistic as a whole, that is the reason why they think writing learning is important but difficult; meanwhile, it indicates that the writing ability has great potential and development space.

Table 3 The pretest attitude of all the samples to multimedia teaching

\begin{tabular}{ll}
\hline Quantity & Value \\
\hline Number of Unique Blogs & 100,649 \\
RSS & $62 \%$ \\
Atom & $38 \%$ \\
\hline First Feed Crawl & $06 / 12 / 2005$ \\
Last Feed Crawl & $21 / 02 / 2006$ \\
\hline Number of Feeds Fetches & 753,681 \\
Number of Permalinks & $3,215,171$ \\
Number of Homepages & 324,880 \\
\hline Total Compressed Size & $25 \mathrm{~GB}$ \\
Total Uncompressed Size & $148 \mathrm{~GB}$ \\
Feeds (Uncompressed) & $38.6 \mathrm{~GB}$ \\
Permalinks (Uncompressed) & $88.8 \mathrm{~GB}$ \\
Homepages (Uncompressed) & $20.8 \mathrm{~GB}$ \\
\hline
\end{tabular}

According to the survey, $53.6 \%$ of the students who have attended English writing course are dissatisfied with teachers' teaching and they also think that classroom teaching is boring, the knowledge is not so practical(actually it is caused by lack of usual practical activities.) and that learned theoretical knowledge can not well link with practice.

All the students have not attended the multimedia auxiliary English writing course. In reference to whether they like it or not, the statistical results are shown in table 2$3,66.9 \%$ of the students are positive and they think that network multimedia teaching can active classroom atmosphere and provide a wealth of information. $33.1 \%$ are negative. They think that in multimedia classroom teachers are just filling the knowledge into students who are very passive. It has to be said here that it results from that teachers dose not use multimedia rationally. Therefore, in order to make network multimedia play its proper role in classroom, teachers have to learn something about media design theory and teaching theory.

Writing is not a learning activity that can not be completed immediately, so how to make students practice writing persistently in the long run, how to cultivate their learning motivation timely and positively and how to improve their learning attitude towards writing skills become the questions that we should focus on. From the interview we can see that students lack initiative and interest in writing; they rely on teachers' explanations and homework supervision; they have no awareness of autonomous learning and lack motivation in learning; if teachers do not assign homework, they are unwilling to write initiatively. The prominent problems in writing are: lack of vocabulary; no ideas; can't apply the vocabulary and sentence patterns which they have learned; many grammatical errors; not coherent in discourse; a lot of short sentences; long sentences do not accord with English usage etc. English composition in Chinese style.

2. Survey results from teachers

Author interviewed dozens of college English teachers including the teachers of English majors and those who teach non-English majors. When it comes to English writing teaching, they think the most headache problems are classroom atmosphere and students' learning attitude. Some teachers are used to just reading the textbook, which greatly foils students' enthusiasm and makes classroom atmosphere dead and students sleepy; some teachers take a certain way to mobilize the classroom atmosphere. But in recent years, the theoretical property of writing course itself is very strong, so the tradition of "heavy theory, light practice" make teachers powerless. The class time is limited, so there is little time left for teachers communicating with students.

Table 4 Investigation results of English writing teachers

\begin{tabular}{|l|l|r|r|r|r|}
\hline N & VOLID & 10 & 10.0000 & 10.0000 & 110.0000 \\
\hline MEAN & MISSING & 0 & 0.0000 & 0.0000 & 0.0000 \\
\hline MEDIAN & & 4.3000 & 4.6000 & 4.3000 & 4.6000 \\
\hline MODO & & 4.0000 & 5.0000 & 4.0000 & 5.0000 \\
\hline STD. & & 674.9000 & 5164.0000 & 345.4000 & 5164.0000 \\
\hline MINIMUM & & 3.4000 & 4.0000 & 3.4000 & 4.0000 \\
\hline MAXIMUM & & 5.0000 & 5.0000 & 5.0000 & 5.0000 \\
\hline SUM & & 43.0000 & 46.0000 & 43.0000 & 46.0000 \\
\hline
\end{tabular}

Results show that, in the cognition of teachers to the importance of each skill during English learning to studying, they think that impact of writing and oral English on English learning is the greatest. Because the statistical samples are less, the difference is not so big.

When it comes to the attitude towards multimedia, $80 \%$ of the teachers support multimedia teaching; but still $20 \%$ are against it. During the interview, some teachers said frankly that they resisted teaching tools such as computer. During the teaching process of modern technology, teachers should realize the teaching advantages of network multimedia and that they need to learn multimedia teaching theory and apply it to teaching practice to adapt to the times. When it comes to teaching problems, most teachers think that because students do not have enough time and chances to collect writing materials during the learning process, their writing content is poor; students lack the chances to externalize the knowledge they've learned in classroom, have little class time and no practice after class, so they lack 
feedback in English writing. However, teachers are powerless. They have a lot of homework to correct but have limited time, so they can find no way out and have to just read the textbook. How to overcome the limit of time and space is a big question for both teachers and students in writing course.

3.Specific Practices of college English Writing Education Supported by Modern Technology

\section{Application of Modern Technology in Classroom Teaching}

Main teaching content of classroom teaching led by teachers mainly includes presentation of composition topics and writing requirements, introduction of writing techniques and methods, and explanation of model essays. The employment of multimedia courseware by teachers can conveniently present multimedia information, such as language and characters, photographs, tables, animations, music, movies and so on. It enables teaching information be presented in various forms, which attracts students' attention and raises their interests. Teachers can first present composition topics in class with PowerPoint, then analyze and explain the language points related to the topics, composition structures and writing materials in detail, as shown in Picture 1 and Picture 2.

Picture 1 To analyze and explain with PPT in class

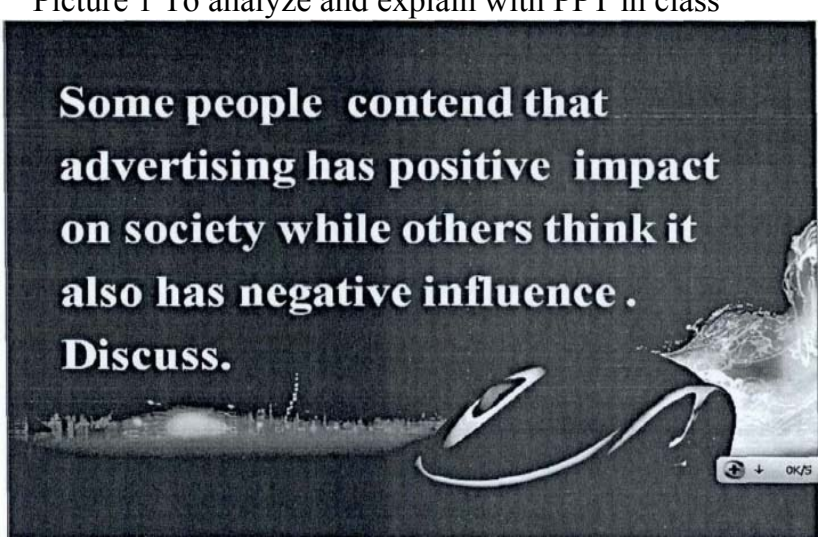

Picture 2 To analyze and explain with PPT in class

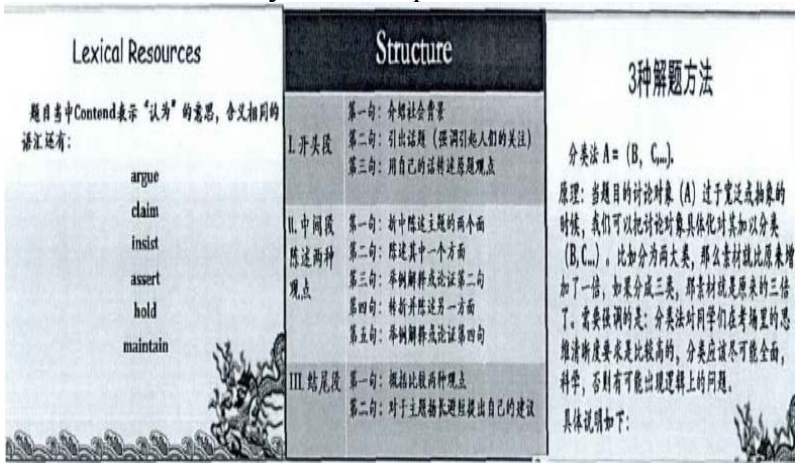

In class, through teacher's explanation, students can recognize the writing requirement of the composition topic, which is, the advantages and disadvantages of advertisement, and master basic writing methods, techniques, and processes, and expand their vocabulary, thus get to understand English writing to some extent.

\section{Set up Writing Platform}

From a technical point of view, BBS itself can turn into a large data base. The BBS of discuz can support various learning resources, which include text files, audio files and video files. Therefore, we can set up a resource database platform with various learning resources through BBS. Secondly, BBS has the function of publishing articles and offering readers reviews, thus it can help realize synchronization between authors and readers or asynchronous communication. According to teaching requirements, the author of this paper divides BBS into several sectors, such as writing resource sector, writing communication sector, students' model essays show sector and writing web links sector. The writing resource sector is further divided into writing theories part, writing techniques and methods part, writing vocabulary and expressions part, essay topics and model essays of CET 4 and CET 6 part, and writing course videos of foreign open courses part, so that students can use, refer to and study these materials in a convenient way. A screenshot of the forum discussed above is shown in Picture 3.

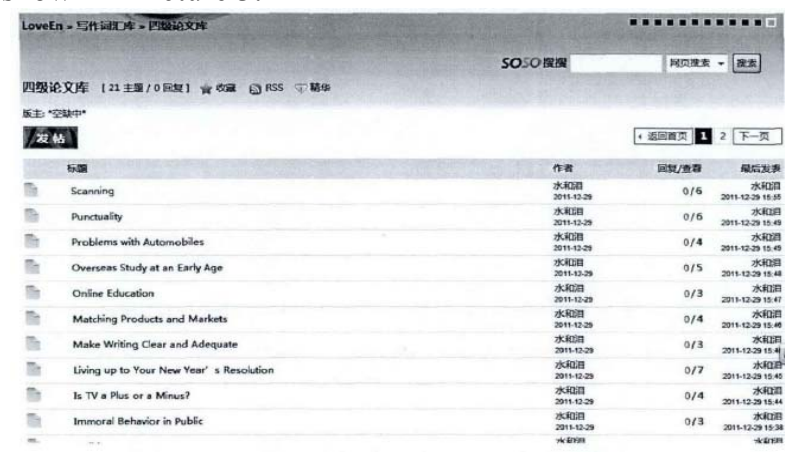

\section{PRE-WRITING}

When students conduct self-directed learning according to teaching prescription, they can collect words, phrases, expressions and writing content (opinions) through visiting the resource part of BBS. They can also accumulate materials, like advantages and disadvantages of advertisement and its examples, by searching key words with network search engines such as Google and Baidu. However, since these collected massive related words, expressions and examples exist in students' mind in the form of fragments, they need to process and dispose these "raw materials". The author requires students to learn to use mind map software, Mindmanager, in order to brain storm these information, sort them out and process them. It can help students get their writing ideas into shape and select examples to support their writing opinions according to needs, so that a general framework of the composition can be formed, as shown in Picture 4. 


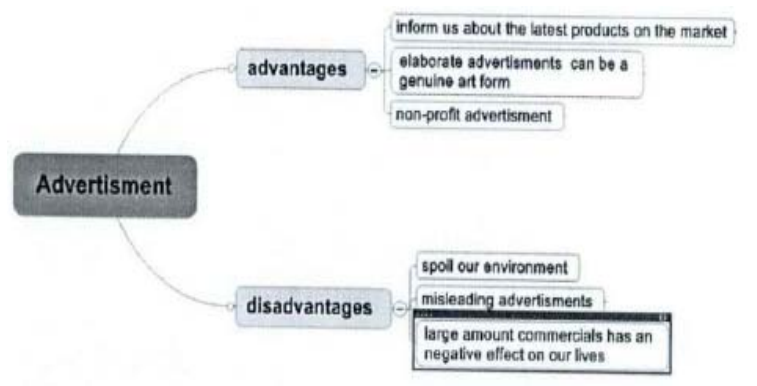

Picture 4 Mind manager

\section{APPLICATION OF MODERN TECHNOLOGY IN LEXICAL EXPRESSION}

In writing process, students can select and use words, phrases and expressions with help of computer software, such as Power Word, Youdao Dict and Baidu Dict (address: http://dict.baidu.com/ ) or corpus to retrieve the use context of some word, in order to know the correct usage of this word. For example, after retrieval of cause in corpus, we can discover that objects used after this word all suggest some bad consequences, which include flood, water and soil erosion, drug addiction, machine malfunction and so on. In other words, once an object is used after the word cause, it will produce some bad associative meanings, as shown in Picture 5.

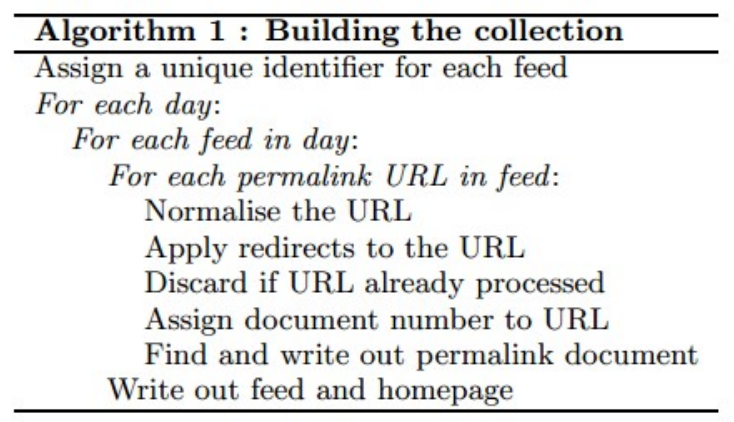

\section{APPLICATION OF MODERN TECHNOLOGY IN SENTENCE EXPRESSION}

The author sets up stylewriter4.0,an English writing polishing software, in client-side of students' computers, which can be used as an independent software, and a plug-in board in word. When students finish their first drafts, they can use stylewriter to realize the analysis and polishing of their essays, and provide some advice for modification. As shown in table 4-8, this is the explanation of wrong punctuation and modifying advice of grammar error in students' compositions. With stylewriter, students first check and analyze their essays by their own, such as word spelling, word collocation and grammar errors, and modify and polish them according to advice offered by stylewriter. In this way, teachers' burden of reviewing essays can be reduced, so that their energy can be focused on guiding students in the content and rhetorical techniques rather than correcting students' spelling mistakes and grammar errors.

\section{FEEDBACKS AND EVALUATIONS BASED ON INTERNET WRITING PLATFORM SYSTEM}

After students modifying their essays preliminarily according to stylewriter software, they can $\log$ in the "English composition training system" of FLTRP (address: http fltrp.pigai.org/index.php? $\mathrm{c}=\mathrm{v} 2 \& \mathrm{a}=$ write $\&$ rid $=10488 \&$ eid $=$ ) to evaluate and grade them. Students first copy the text into the writing sector of this training system, and then the system will analyze and evaluate this text from four aspects, namely vocabulary, sentences, passage structures and content. It will grade and give comments according to the results of general analysis and evaluation, as shown in table 5. In addition to this, this "English composition training system" analyzes students' essays sentence by sentence, makes positive and negative assessments, and provides advice for modification.

\begin{tabular}{|l|l|c|c|c|c|}
\hline Group & Run & MAP & R-prec & b-Bref & P@10 \\
\hline UIC (Zhang) & uiclc & $\mathbf{0 . 4 3 4 1}$ & $\mathbf{0 . 4 5 2 9}$ & $\mathbf{0 . 4 7 2 4}$ & $\mathbf{0 . 6 9 0}$ \\
UAmsterdam (deRijke) & uams07topic & 0.3453 & 0.3872 & 0.3953 & 0.562 \\
UGlasgow (Ounis) & uogBOPFProxW & 0.3264 & 0.3657 & 0.3497 & 0.552 \\
DalianU (Yang) & DUTRun2 & 0.3190 & 0.3671 & 0.3686 & 0.600 \\
FudanU (Wu) & FDUTOSVMSem & 0.3143 & 0.3465 & 0.3499 & 0.460 \\
CAS (Liu) & Relevant & 0.3041 & 0.3600 & 0.3779 & 0.446 \\
UArkansas Littlerock (Bayrak) & UALR07BlogIU & 0.2911 & 0.3263 & 0.3134 & 0.580 \\
IndianaU (Yang) & oqsnr2opt & 0.2894 & 0.3572 & 0.3419 & 0.532 \\
UNeuchatel (Savoy) & UniNEblog1 & 0.2770 & 0.3353 & 0.3074 & 0.492 \\
FIU (Netlab team) & FIUbPL2 & 0.2728 & 0.3204 & 0.2925 & 0.454 \\
UWaterloo (Olga) & UWopinion3 & 0.2631 & 0.3344 & 0.2980 & 0.496 \\
Zhejiangu (Qiu) & EAGLE1 & 0.2561 & 0.3159 & 0.2867 & 0.428 \\
CAS (NLPR-IACAS) & NLPRPST & 0.2542 & 0.3168 & 0.2945 & 0.462 \\
BUPT (Weiran) & prisOpnBasic & 0.2466 & 0.3018 & 0.2835 & 0.456 \\
KobeU (Eguchi) & KobePrMIR01 & 0.246 & 0.3011 & 0.2744 & 0.440 \\
NTU (Chen) & NTUAutoOp & 0.2282 & 0.2614 & 0.2577 & 0.464 \\
KobeU (Seki) & Ku & 0.1689 & 0.2417 & 0.2190 & 0.254 \\
RGU (Mukras) & rgu0 & 0.1686 & 0.2266 & 0.2163 & 0.288 \\
UBuffalo (Ruiz) & UB2 & 0.1013 & 0.1297 & 0.1238 & 0.144 \\
Wuhan (Lu) & NOOPWHU1 & 0.0011 & 0.0071 & 0.0072 & 0.008 \\
\hline
\end{tabular}

\section{AFTER-CLASS TUTORING WITH MICROBLOG TECHNOLOGY}

With search function, students can find some microblogs related to English learning and pay attention to them. Through the attention paid to professional microblogs, they can obtain updated information from the microblogger at any time and transmit them. Moreover, students can join microblog groups and participate in others' discussion of English learning. With the interaction between teachers and students, and between students and online English learners, students' interests of learning English can be cultivated and their enthusiasm of participating in English learning discussion can be enhanced, as shown in Picture 6. 


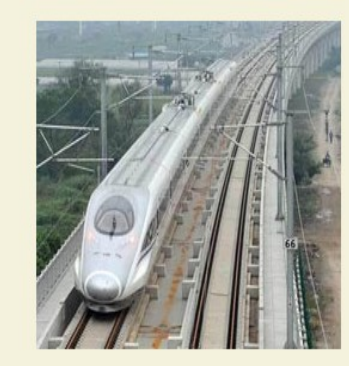

A train runs on Shanghai-Hangzhou High-Speed Railway, Sept. 28, 2010. The train CRH380A which on Tuesday started trial operation on the Shanghai-Hangzhou High-Speed railway set a new speed record of 416.6 kilometers per hour.

\section{REFERENCES}

[1] IT-based language instruction. Teaching of English Language and Literature, 13(2), 5-8. Jacqueline S.

[2] Thousand, et al. (2002). Creativity and Collaborative Learning[C]. by Brookes PublishingCo.,Baltimore, MD. pp. 31-44

[3] http://benjamin3584.blog.163.com/blog/static/4469312006109344544 $71 /$

[4] Gabriela Grosseck , Carmen Holotescu. Can We Use TwitterForEducationalActivities?[EB/OL].http://adlunap.ro/else/pape rs/015.697.1.Grosseck\%20GabrielaCan\%20we\%20use.pdf. 2010-0425/2012-02-12.

[5] http://baike.baidu.com/view/2135775.htm.2007-07-27/2012-02-12.

[6] blog and micro-blogging

[7] http://dev.fanfou.com/wpcontent/uploads/2007/09/microblogging.pdf, 2008-06-19/ 